\title{
Liquid-formed Glassy Film of N,N'-diphenyl-N,N'-bis(3-methyl)-benzidine: Formation, Carrier Transporting Ability, Photoluminescence and Stability
}

\author{
Liang Chen, Guifang Dong, Lian Duan, Liduo Wang, Juan Qiao, Deqiang Zhang and \\ Yong Qiu* \\ Key Lab of Organic Optoelectronics \& Molecular Engineering of Ministry of \\ Education, Department of Chemistry, Tsinghua University, Beijing 100084, China \\ E-mail: qiuy@mail.tsinghua.edu.cn
}

Tel: (008610) 62788802, Fax: (008610) 62795137

Supporting information 
A. The morphology of the glassy films prepared by vacuum deposition process with different parameters

To study the morphology and stabilities of the films prepared by vacuum deposition, we have changed the source temperature and obtained the glassy films (thickness: $150 \mathrm{~nm}$ ) with different deposition rates. Notice that the substrate was not heated during deposition. The images obtained by optical microscope and AFM were illustrated in Figure A1 and A2, respectively, and the critical experimental data were list in Table A1. In agreement with the previous report [1], when the deposition rate was $0.3 \mathrm{~nm} / \mathrm{s}$, the surface of TPD film is flattest. However, though the film deposited at $0.3 \mathrm{~nm} / \mathrm{s}$ had the best morphology, the liquid-formed glassy film of $5.2 \mu \mathrm{m}$ thickness has a $R_{r m s}$ of only $0.9 \mathrm{~nm}$ and shows the flatter surface.
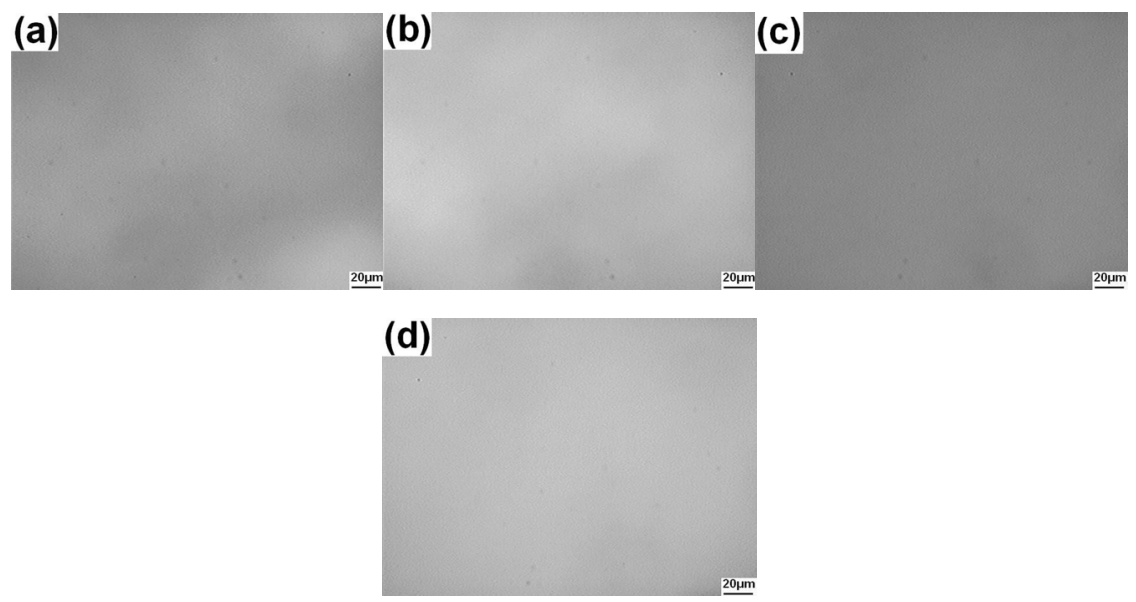

Figure A1. The optical microscope images of vacuum deposited TPD films with different deposition rates: (a) $0.03 \mathrm{~nm} / \mathrm{s}$; (b) $0.1 \mathrm{~nm} / \mathrm{s}$; (c) $0.3 \mathrm{~nm} / \mathrm{s}$; (d) $0.5 \mathrm{~nm} / \mathrm{s}$.
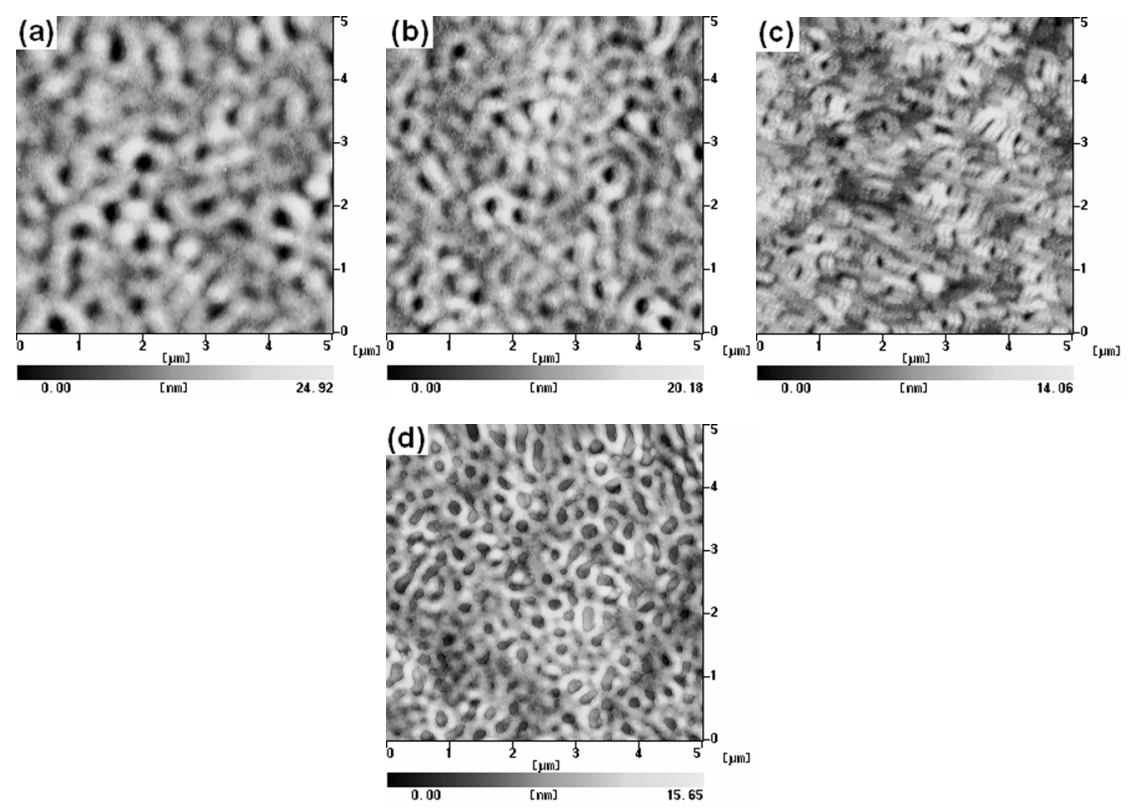

Figure A2. The AFM images of vacuum deposited TPD films with different deposition rates: (a) 
$0.03 \mathrm{~nm} / \mathrm{s}$; (b) $0.1 \mathrm{~nm} / \mathrm{s}$; (c) $0.3 \mathrm{~nm} / \mathrm{s}$; (d) $0.5 \mathrm{~nm} / \mathrm{s}$.

Table A1 The morphology of the TPD films with different deposition rates

\begin{tabular}{cccccc}
\hline & $\begin{array}{c}\text { Source } \\
\text { temperature } /{ }^{\circ} \mathrm{C}\end{array}$ & $\begin{array}{c}\text { Deposition } \\
\text { rate/(nm/s) }\end{array}$ & Thickness $/ \mathrm{nm}$ & $R_{r m s} / \mathrm{nm}$ & $\begin{array}{c}\text { Peak to } \\
\text { Valley/nm }\end{array}$ \\
\hline 1 & $170 \sim 172$ & 0.03 & 150 & 3.864 & 34.35 \\
2 & $185 \sim 188$ & 0.1 & 150 & 3.137 & 28.89 \\
3 & $201 \sim 205$ & 0.3 & 150 & 2.234 & 17.14 \\
4 & $213 \sim 216$ & 0.5 & 150 & 2.497 & 19.08 \\
\hline
\end{tabular}

As seen the optical microscope and AFM images in Figure A3 and A4, after the heating treatment at $70^{\circ} \mathrm{C}$ in air for 3 hours, all the films prepared by vacuum deposition are partially crystallized. In the crystalline region, the P-V distance is greatly over $150 \mathrm{~nm}$ which was the film thickness, indicating that the film uniformity is destroyed. There is no observable change in the rapidly-cooled film after same treatment.
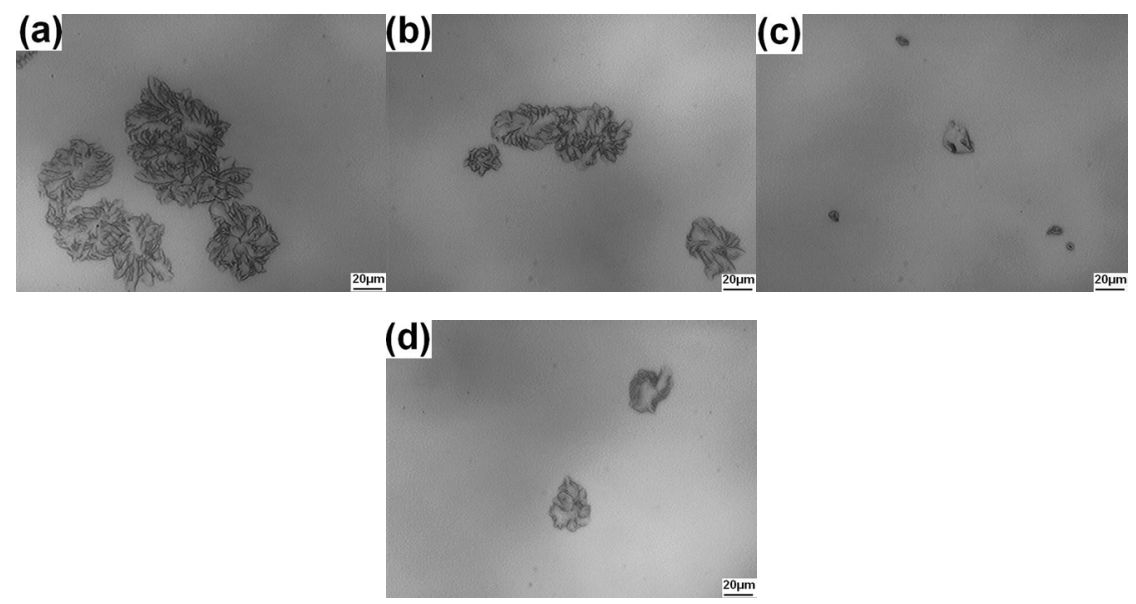

Figure A3. The optical microscope images of the TPD films with different deposition rates after the heat treatment at $70^{\circ} \mathrm{C}$ in air for 3 hours: (a) $0.03 \mathrm{~nm} / \mathrm{s}$; (b) $0.1 \mathrm{~nm} / \mathrm{s}$; (c) $0.3 \mathrm{~nm} / \mathrm{s}$; (d) $0.5 \mathrm{~nm} / \mathrm{s}$.
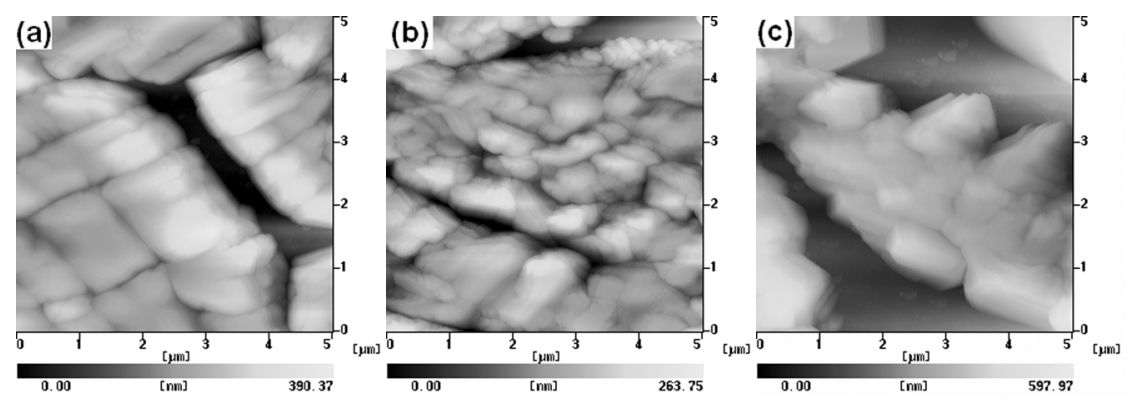


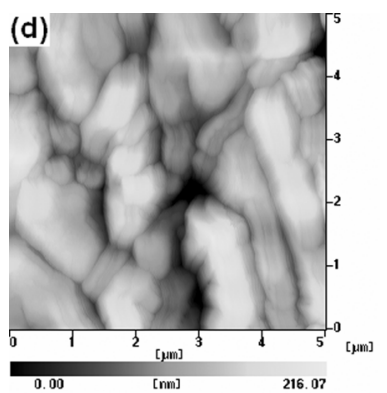

Figure A4. The AFM images of crystalline regions of the TPD films with different deposition rates after the heat treatment at $70^{\circ} \mathrm{C}$ in air for 3 hours: (a) $0.03 \mathrm{~nm} / \mathrm{s}$; (b) $0.1 \mathrm{~nm} / \mathrm{s}$; (c) $0.3 \mathrm{~nm} / \mathrm{s}$; (d) 0.5 $\mathrm{nm} / \mathrm{s}$.

Another experiment was carried out to find out the dependence between the substrate temperature and the film morphology. TPD were deposited at different substrate temperature (room temperature, $50^{\circ} \mathrm{C}$ and $70^{\circ} \mathrm{C}$ ) and the deposition rates were kept at $0.3 \mathrm{~nm} / \mathrm{s}$. Figure A5 and A6 showed the optical microscope and AFM images of the vacuum deposited films, respectively. When the glass substrate was heated at $50^{\circ} \mathrm{C}$ during deposition, the film looks uniform and the $R_{r m s}$ of the $150 \mathrm{~nm}$-thick film is slightly rose to $2.549 \mathrm{~nm}$ in comparison with the sample prepared at normal substrate temperature. The organic molecules start to aggregate when the substrate temperature was $70^{\circ} \mathrm{C}$ which is higher than $T_{g}$ of TPD. The P-V distance is about $900 \mathrm{~nm}$. Crystalline regions also can be found in the surface of the film fabricated at a substrate temperature of $50^{\circ} \mathrm{C}$ after the heating treatment at $70^{\circ} \mathrm{C}$ in air for 3 hours.

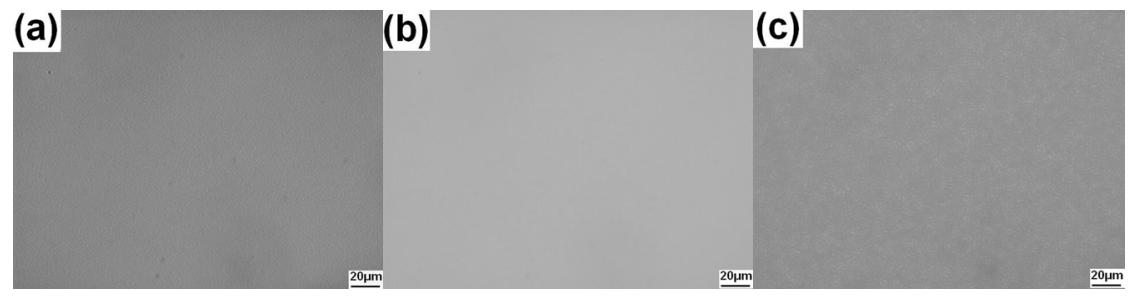

Figure A5. The optical microscope images of vacuum deposited TPD films with different substrate temperature: (a) room temperature; (b) $50^{\circ} \mathrm{C}$; (c) $70^{\circ} \mathrm{C}$.
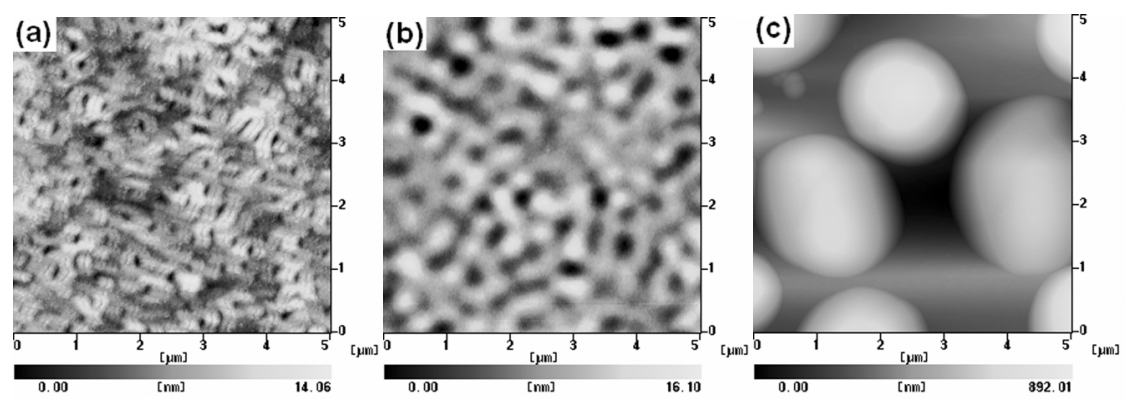

Figure A6. The AFM images of vacuum deposited TPD films with different substrate temperature: (a) room temperature; (b) $50^{\circ} \mathrm{C}$; (c) $70^{\circ} \mathrm{C}$.

Table A2 The morphology of the TPD films at different deposition substrate temperatures 


\begin{tabular}{cccccc}
\hline & $\begin{array}{c}\text { Substrate } \\
\text { temperature } /{ }^{\circ} \mathrm{C}\end{array}$ & $\begin{array}{c}\text { Deposition } \\
\text { rate/(nm/s) }\end{array}$ & Thickness $/ \mathrm{nm}$ & $R_{r m s} / \mathrm{nm}$ & $\begin{array}{c}\text { Peak to } \\
\text { Valley } / \mathrm{nm}\end{array}$ \\
\hline 1 & $\mathrm{RT}^{\mathrm{a}}$ & 0.3 & 150 & 2.234 & 17.14 \\
2 & 50 & 0.3 & 150 & 2.549 & 19.95 \\
3 & 70 & 0.3 & 150 & 171.5 & 892.0 \\
\hline
\end{tabular}

${ }^{\mathrm{a}} \mathrm{RT}=$ room temperature

B. The cooling rate of the rapidly-cooled sample

In the rapid-cooling method, TPD sample was heated on a hotplate until it melted, and then cooled on an iron plate at room temperature. The cooling rate was dependent on time, and the average was around $5^{\circ} \mathrm{C} / \mathrm{s}$ in the range of $185^{\circ} \mathrm{C} \sim 30^{\circ} \mathrm{C}$. The sample temperature versus time characteristics during cooling was shown in Figure B.

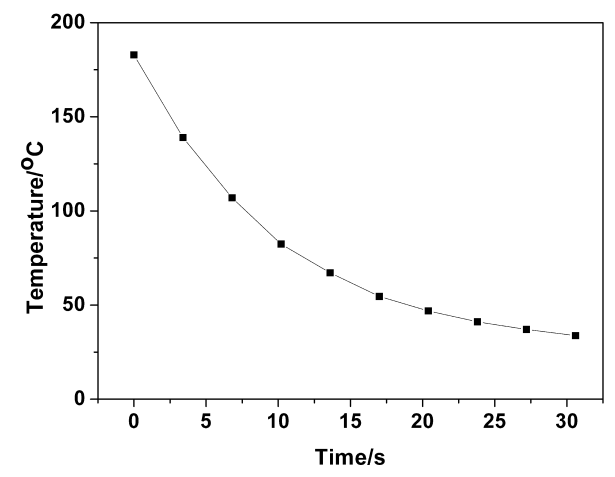

Figure B. The temperature versus time curve during cooling process.

\section{IR spectra of samples}

IR spectra of two TPD samples were illustrated in Figure C. Sample A: vacuum deposited film $(200 \mathrm{~nm})$; Sample B: rapidly-cooled film $(5.2 \mu \mathrm{m})$. The positions and relative intensities of main peaks of the IR spectra were almost the same, suggesting that no thermal induced degradation of the compound occurred during the film fabrication.

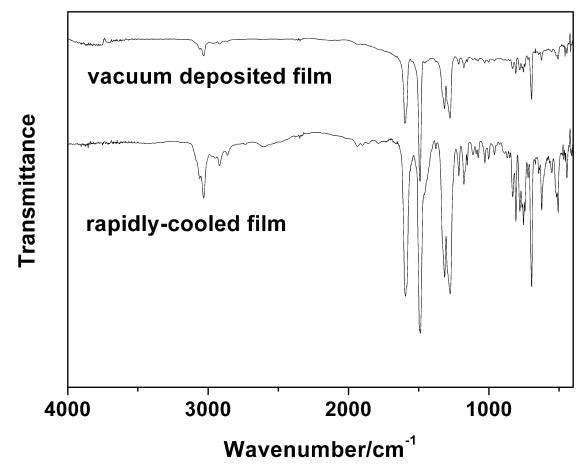

Figure C. IR spectra of two TPD samples. 


\section{XRD patterns of samples}

The X-ray diffraction of the rapidly-cooled film $(150 \mathrm{~nm})$ and the vacuum deposited film $(5.2 \mu \mathrm{m})$ at room temperature were illustrated in Figure D. The vacuum deposited film was fabricated at $0.3 \mathrm{~nm} / \mathrm{s}$. No noticeable diffraction peak can be observed, indicating that these thin films are amorphous or slightly crystallized with crystallinity lower than the limit of detection of XRD test. The broad bands between $10^{\circ}$ and $40^{\circ}$ are detected for the glass substrate.

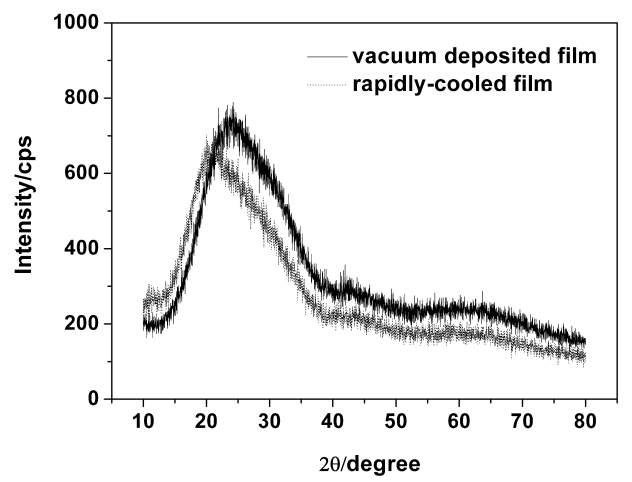

Figure D. X-ray diffraction from vacuum deposited film and rapidly-cooled film of TPD.

\section{Reference}

[1] M. Mandai, K. Takada, T. Aoki, T. Fujinami, Y. Nakanishi, Y. Hatanaka, Synth. Metal. 1997, $91,123$. 